\title{
Microwave Assisted Acid Digestion of Biomorphic Ceramic Obtained from Beech Wood Infiltrated with Nickel Oxide: Factorial Design
}

\author{
F. Sánchez Rojas ", C. Bosch Ojeda, J. M. Cano Pavón \\ Department of Analytical Chemistry, Faculty of Sciences, University of Málaga, Campus Teatinos s/n, 29071, Málaga, Spain
}

\begin{abstract}
Biomorphic ceramics is a novel inorganic materials with hierarchical structures derived from natural biological structures. This work describes the use of experimental design for optimization of microwave-assisted digestion of biomorphic NiO-ceramic. Beech wood is used as template and it was infiltrated with NiO. XPS and SEM have been used to verify the effectiveness of the synthesis. The effects of different combination of acids in the digestion of this sample have been optimized taking as response the concentration of several metallic ions measured by flame atomic absorption spectrometry (FAAS).
\end{abstract}

Keywords Biomorphic, Beech Wood, Factorial Design, Microwave Digestion, FAAS

\section{Introduction}

In the last decade, a new class of ceramic materials has attained particular attention. The materials were produced with natural, renewable resources (for example, wood or wood-based products). A considerable interest has been shown in the synthesis of materials of biomorphic microstructure[1]. The biological structures present a constructed anatomy hierarchically, developed and optimized throughout the evolutionary process, giving like result relations between the mechanical properties and the microstructure, that are unique and have happened to be of great interest for the advanced processing in the last years. Due to the processes of genetic evolution, the biological structures exhibit, a low density, an excellent resistance, high hardness and elasticity, and tolerance to the damage as much to micro as on macro-scale[2]. The fact that the trees are able to remain right as beams during hundreds of years is due to the high level of its mechanical properties[3]. The wood is a composed natural material with an architecture where bio-polymeric like cellulose, hemi-cellulose and lignin they form a cellular microstructure of high porosity that, nevertheless, exhibits an extraordinary combination of resistance, rigidity and hardness, for that reason, the wood use as material template, or material giver of the structure, produces ceramic materials with high and directed porosity combined with the necessary resistance for applications like acoustic

* Corresponding author:

fsanchezr@uma.es (F. Sánchez Rojas)

Published online at http://journal.sapub.org/chemistry

Copyright (C) 2012 Scientific \& Academic Publishing. All Rights Reserved and thermal insulating structures[4,5]. The mechanical properties and physical structure of the biomorphic materials have been studied in order to obtain information for its practical use. Generally, in the ceramic derived from wood, the mechanical properties increase with fractional density; strength and strain-to-failure in axial direction exhibit significantly higher values compared to loading in radial and tangential directions. Moreover, the elastic module and fracture toughness of biomorphic ceramics strongly depend on the properties of starting wood performs. Chemical composition of the biomorphic materials has been scarcely investigated. These materials contains impurities and co-milling of the binary compounds leads to heterogeneous distribution of impurities, which impairs the mechanical and physical properties of the final ceramic, so that the chemical analysis of these biomorphic materials is very impor$\operatorname{tant}[6-14]$.

Generally, wood ceramics are fabricated through three steps: 1) formation of bio-carbon template by pyrolyzing the wood materials; 2) infiltration of the bio-carbon template with ceramic precursors; 3) calcination to form ceramics and remove organic materials. Carbides and carbide composites are most reported due to carbonaceous nature of the wood template, but a range of ceramic materials, including oxides, nitrides, and zeolites, were also produced by employing proper precursors and reaction routes. In this way, $\mathrm{SiO}_{2}$ replicas of wood tissues can be obtained by infiltration with Si-containing sols, which decompose into $\mathrm{SiO}_{2}$ during subsequent heat treatment in air. Metal oxides can be obtained using metal salt or metal alkoxide infiltrants, which subsequently undergo oxidation reactions to form metal oxides. For example, Ota et al.[15] formed porous 
$\mathrm{TiO}_{2}$ by infiltrating wood with titanium tetraisopropoxide sol. A titania gel formed as a result of hydrolysis of the sol; subsequent calcination in air yielded $\mathrm{TiO}_{2}$ ceramic retaining the original wood morphology. Cao et al.[14] formed $\mathrm{Al}_{2} \mathrm{O}_{3}$ ceramic with rattan and pine using a low viscous alumina sol. The $\mathrm{Al}_{2} \mathrm{O}_{3}$ ceramics were highly porous, exhibiting morphology of the wood. Fan et al.[16] synthesized $\mathrm{Cr}_{2} \mathrm{O}_{3}$ ceramic by immersing wood in chromium nitrate solution. The $\mathrm{Cr}_{2} \mathrm{O}_{3}$ ceramics inherited macro- and microstructures of the original wood, and showed a hierarchical porosity from micro- to nanoscales. Li et al.[17] produced a hierarchically porous manganese oxide wood ceramic using manganese nitrate as the precursor. Liu et al.[18] produced nickel oxide from a pinewood template using hydrothermal synthesis and nickel nitrate as the precursor. Rambo et al.[19] formed yttria-stabilize zirconia ceramic using zirconium- oxychloride sol with yttrium nitrate added to stabilize tetragonal $\mathrm{ZrO}_{2}$ as the precursor. Singh and Yee[20] synthesized $\mathrm{ZrO}_{2}$ ceramic by infiltrating $\mathrm{ZrO}_{2}$ sols into the wood preform.

In this work, a biomorphic material derived from beech wood is synthesized based on NiO. XPS and SEM have been used for to verify the effectiveness of the synthesis. Factorial design strategy has been used to microwave assisted acid digestion taking as dependent variable the element concentrations measured by FAAS ( $\mathrm{Ca}$ and $\mathrm{Mg}$ presents in the native wood and $\mathrm{Ni}$ added as infiltration agent).

\section{Experimental}

\subsection{Instrumentation}

A Lenton Tube furnace, model LTF 16/180, was employed for the synthesis of biomorphic ceramics.

X-ray photoelectron spectroscopy (XPS) analysis was performed with a Physical Electronics 5700 instrument with a $\mathrm{Mg} \mathrm{K} \alpha \mathrm{X}$-ray excitation source $(\mathrm{h} v=1253.6 \mathrm{eV})$; binding energies (BE) were determined with respect to the position of the $\mathrm{C} 1 \mathrm{~s}$ peak at $284.5 \mathrm{eV}$. The residual pressure in the analysis chamber was maintained below $133 \times 10^{-9} \mathrm{~Pa}$ during data acquisition.

Scanning electronic microscopy (SEM) JEOL, Model SM-6490LV was used to obtain the micrographs shown in Figure 1 and semi-quantitative analysis shown in Table 1.

Table 1. Semi-quantitative analysis from SEM

\begin{tabular}{cccc}
\hline Spectrum & $\mathrm{C}$ & $\mathrm{O}$ & $\mathrm{Ni}$ \\
\hline Line 1 & 65.78 & 16.40 & 17.82 \\
Line 2 & 46.37 & 11.45 & 42.18 \\
Line 3 & 29.61 & 9.53 & 60.86 \\
Mean & 47.25 & 12.46 & 40.29 \\
Std. Dev. & 18.10 & 3.55 & 21.58 \\
Max. & 65.78 & 16.40 & 60.86 \\
Min. & 29.61 & 9.53 & 17.82 \\
\hline
\end{tabular}

A Panasonic (National) microwave oven, model NN8507, and a Parr Microwave Acid Digestion Bomb, model 4782, were used for sample digestion. The bombs were cleaned before use with $10 \%(\mathrm{v} / \mathrm{v}) \mathrm{HNO}_{3}$ for 1 day followed by repeated rinsing with water.

A Varian Model SpectrAA 50 (Mulgrave, Victoria, Australia) flame atomic absorption spectrometer was used for the $\mathrm{Ni}, \mathrm{Ca}$, and $\mathrm{Mg}$ analysis with the appropriate hollow cathode lamp.

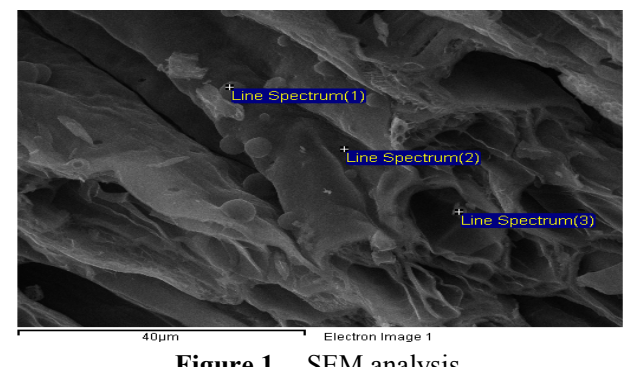

Figure 1. SEM analysis

\subsection{Reagents}

Analytical reagent grade chemicals were used throughout. $\mathrm{Ni}\left(\mathrm{NO}_{3}\right)_{2} \cdot 6 \mathrm{H}_{2} \mathrm{O}$ (Merck) for infiltration into the porous biological templates. Standard $1000 \mu \mathrm{g} \mathrm{mL}^{-1} \mathrm{Ni}(\mathrm{II}), \mathrm{Ca}(\mathrm{II})$ and $\mathrm{Mg}$ (II) solutions (Fluka) were used. Standards of working strength were made by appropriate dilution as required immediately prior to use. Water was deionised with a Milli-Q system. Concentrated acid $\mathrm{HCl}, \mathrm{HF}, \mathrm{H}_{2} \mathrm{SO}_{4}$ and $\mathrm{HNO}_{3}$ (Merck) were used for digestion of the samples.

\subsection{Synthesis}

The procedure employed in the synthesis of this material, has been taken of the proposed by Liu et al.[18].

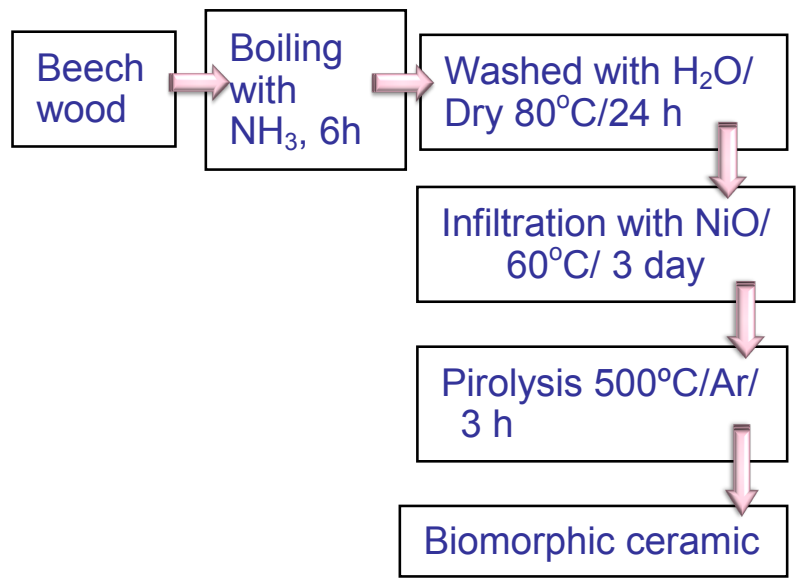

Figure 2. Schematic diagram employed for biomorphic ceramic based on $\mathrm{NiO}$

Beech wood pieces with a dimension of $34 \times 30 \times 7 \mathrm{~mm}^{3}$ were employed. Extractives such as resins, salts, and glues in the wood were removed using boiling 5\% ammonia solution for $6 \mathrm{~h}$ before precursor infiltration. Extracted specimens were washed with deionized water and dried at $80^{\circ} \mathrm{C}$ for $24 \mathrm{~h}$. The precursor solution for $\mathrm{NiO}$ was prepared with $30 \mathrm{mmol}$ $\mathrm{Ni}\left(\mathrm{NO}_{3}\right)_{2}$ dissolved in a mixture solvent of $10 \mathrm{~mL}$ ethanol and $5 \mathrm{~mL} \mathrm{H}_{2} \mathrm{O}$. A high volume ratio of ethanol could provide enough $\left[\mathrm{OH}^{-}\right]$for the hydrolysis of nitrate salt. Later, the samples were dipped in the precursor solution at $60^{\circ} \mathrm{C}$ for 72 $\mathrm{h}$ in a glass container. New precursor solution was supple- 
mented, as liquid evaporates, to keep the specimens submerged. Finally, the samples were taken out from the solution and air dried at $60^{\circ} \mathrm{C}$ for $24 \mathrm{~h}$, calcined at $500^{\circ} \mathrm{C}$ for $3 \mathrm{~h}$ in the argon atmosphere. The procedure was described by the schematic diagram in Figure 2.

\subsection{Microwave-assisted Pressure Digestion with Acids}

In a preliminary step, $10 \mathrm{mg}$ of sample were weighed accurately and the corresponding acid mixtures were added to the digestion vessels and were treated for $2 \mathrm{~min}$ to maximum power $(700 \mathrm{~W})$. Mixtures of acids were employing following the order given in Table 2. The volume of these mixtures is taken randomly. The dissolutions obtained were completely transferred into a $25 \mathrm{~mL}$ calibrated flasks and diluted to volume with water. Then, these dissolutions were measured by FAAS and taking as response variable the concentrations of several ions to select the better mixture of acids. From these data we concluded the best acid mixtures were $\left(\mathrm{HNO}_{3}+\mathrm{HCl}\right)$.

After, three factors were studied: power, digestion time and volume of acid selected. A common experimental design is one with all input factors set at three levels each. These levels are called "high", "medium" and "low" or "+1", " 0 " and "-1", respectively. A design with all possible high/ medium/low combinations of all the input factors is called a full factorial design in three levels. A three-level $3^{3}$ full factorial design with 27 runs (in duplicates) was developed in order to determine the influence of the factors and their interactions on the system. The different levels of the variables are shown in Table 3.

Table 2. Preliminary test

\begin{tabular}{|c|c|}
\hline Sample & \\
\hline 1 & $4 \mathrm{ml} \mathrm{HCl}+1 \mathrm{ml} \mathrm{HF}$ \\
\hline 2 & $4 \mathrm{ml} \mathrm{HNO}{ }_{3}+1 \mathrm{ml} \mathrm{HF}$ \\
\hline 3 & $4 \mathrm{ml} \mathrm{H}_{2} \mathrm{SO}_{4}+1 \mathrm{ml} \mathrm{HF}$ \\
\hline 4 & $1 \mathrm{ml} \mathrm{HNO}_{3}+3 \mathrm{ml} \mathrm{HCl}$ (aqua regia) \\
\hline 5 & $4 \mathrm{ml} \mathrm{HCl}+4 \mathrm{ml} \mathrm{H}_{2} \mathrm{SO}_{4}$ \\
\hline 6 & $4 \mathrm{ml} \mathrm{HNO} 3+4 \mathrm{ml} \mathrm{H}_{2} \mathrm{SO}_{4}$ \\
\hline 7 & $3 \mathrm{ml} \mathrm{HCl}+1 \mathrm{ml} \mathrm{HNO}_{3}+1 \mathrm{ml} \mathrm{HF}$ \\
\hline 8 & $4 \mathrm{ml} \mathrm{HCl}+1 \mathrm{ml} \mathrm{H}_{2} \mathrm{SO}_{4}+1 \mathrm{ml} \mathrm{HF}$ \\
\hline 9 & $3 \mathrm{ml} \mathrm{HCl}+4 \mathrm{ml} \mathrm{H}_{2} \mathrm{SO}_{4}+1 \mathrm{ml} \mathrm{HNO}_{3}$ \\
\hline 10 & $4 \mathrm{ml} \mathrm{H}_{2} \mathrm{SO}_{4}+4 \mathrm{ml} \mathrm{HNO}{ }_{3}+1 \mathrm{ml} \mathrm{HF}$ \\
\hline
\end{tabular}

Table 3. Levels of the variables for $3^{3}$ design

\begin{tabular}{ccccc}
\hline Variable & Unit & $\begin{array}{c}\text { Lower level } \\
(-1)\end{array}$ & $\begin{array}{c}\text { Middle level } \\
(0)\end{array}$ & $\begin{array}{c}\text { Upper level } \\
(+1)\end{array}$ \\
\hline Vol. Aqua regia & $\mathrm{ml}$ & 4 & 6 & 8 \\
Power $^{*}$ & $\%$ & 50 & 80 & 100 \\
Time & min. & 2 & 4 & 6 \\
\hline
\end{tabular}

* Power (\%): 100\%=700W; 80\%=560W; 50\%=350W

The experimental sequence of the experiments is shown in Table 4. The experimental data were processed making use of the STATGRAPHICS 5.1 plus program[21]. The significance of the effects was done by analysis of variance (ANOVA) and using p-value significance levels. This value represents the probability of the effect of a factor being due solely to random error. Thus, if the p-value is less than $5 \%$, the effect of corresponding factor is significant. The effects and significance of the variables in the microwave-assisted digestion system were evaluated using Pareto's charts. The length of each bar is proportional to the absolute value of its associated regression coefficient or estimated effect. The effects of all parameters, interactions as well as quadratic terms, are standardised (each effect is divided by its standard error). The order in which the bars are displayed corresponds to the order of the size of the effect. The chart includes a vertical line that corresponds to the $95 \%$ limit indicating statistical significance. An effect is, therefore, significant if its corresponding bar crosses this vertical line.

Table 4. Matrix of the design variables: Factorial $3^{3}$

\begin{tabular}{|c|c|c|c|c|c|c|}
\hline EJECUTION & $\begin{array}{c}\text { VOL. } \\
\text { AR } \\
(\mathrm{mL}) \\
\end{array}$ & $\begin{array}{c}\text { POWER }{ }^{*} \\
(\%)\end{array}$ & $\begin{array}{l}\text { TIME } \\
(\mathrm{min})\end{array}$ & $\begin{array}{c}{[\mathrm{Ni}]} \\
(\mathrm{mg} / \mathrm{g})\end{array}$ & $\begin{array}{c}{[\mathrm{Ca}]} \\
(\mathrm{mg} / \mathrm{g})\end{array}$ & $\begin{array}{c}{[\mathrm{Mg}]} \\
(\mathrm{mg} / \mathrm{g})\end{array}$ \\
\hline 1 & 4.0 & 100 & 6.0 & 370.30 & 52.50 & 6.71 \\
\hline 2 & 6.0 & 50 & 6.0 & 243.92 & 45.41 & 4.58 \\
\hline 3 & 8.0 & 80 & 2.0 & 198.01 & 59.14 & 4.49 \\
\hline 4 & 4.0 & 80 & 2.0 & 353.09 & 42.38 & 7.48 \\
\hline 5 & 8.0 & 80 & 4.0 & 414.15 & 50.29 & 7.54 \\
\hline 6 & 6.0 & 80 & 6.0 & 422.65 & 70.19 & 8.22 \\
\hline 7 & 8.0 & 80 & 6.0 & 373.13 & 60.74 & 6.97 \\
\hline 8 & 6.0 & 50 & 4.0 & 353.98 & 73.15 & 7.47 \\
\hline 9 & 6.0 & 100 & 2.0 & 493.55 & 45.41 & 6.21 \\
\hline 10 & 4.0 & 50 & 6.0 & 301.33 & 48.08 & 3.77 \\
\hline 11 & 4.0 & 50 & 2.0 & 307.89 & 39.23 & 5.19 \\
\hline 12 & 6.0 & 100 & 6.0 & 491.63 & 41.03 & 6.40 \\
\hline 13 & 4.0 & 80 & 4.0 & 326.33 & 31.35 & 3.51 \\
\hline 14 & 4.0 & 100 & 4.0 & 522.70 & 51.47 & 5.74 \\
\hline 15 & 8.0 & 100 & 2.0 & 263.35 & 36.66 & 4.94 \\
\hline 16 & 4.0 & 50 & 4.0 & 209.35 & 70.30 & 8.60 \\
\hline 17 & 8.0 & 50 & 4.0 & 274.12 & 50.97 & 5.95 \\
\hline 18 & 8.0 & 50 & 2.0 & 222.19 & 43.66 & 6.83 \\
\hline 19 & 6.0 & 80 & 2.0 & 213.97 & 47.14 & 5.74 \\
\hline 20 & 8.0 & 100 & 4.0 & 305.90 & 61.71 & 5.19 \\
\hline 21 & 6.0 & 50 & 2.0 & 198.60 & 57.98 & 7.59 \\
\hline 22 & 8.0 & 100 & 6.0 & 281.22 & 64.48 & 6.98 \\
\hline 23 & 8.0 & 50 & 6.0 & 205.76 & 54.17 & 6.25 \\
\hline 24 & 6.4 & 80 & 4.0 & 277.16 & 67.98 & 6.96 \\
\hline 25 & 4.0 & 80 & 6.0 & 349.25 & 81.25 & 4.63 \\
\hline 26 & 4.0 & 100 & 2.0 & 233.20 & 68.82 & 6.48 \\
\hline 27 & 6.0 & 100 & 4.0 & 290.68 & 72.44 & 4.18 \\
\hline
\end{tabular}

*Power (\%): $100 \%=700 \mathrm{~W} ; 80 \%=560 \mathrm{~W} ; 50 \%=350 \mathrm{~W}$

\section{Results and Discussion}

\subsection{XPS Analysis}

XPS has been used for the study of the surface composition of the sample. For this study the biomorphic materials were powdered and homogenized in an agate mortar. Measurements were performed on samples mounted in a cup $(1 \mathrm{~mm} \times 3.5 \mathrm{~mm}$ i.d. $)$ and pressed manually.

XPS spectrum obtained is shown in Figure 3. Consequently, the performance of the synthesis of biomorphic ceramics can be evaluated approximately from these data.

The atomic concentration calculation is expressed as a percentage in a tabular form based on the area under the peak, multiplied by the sensitivity factor for each element, and 
provides a ratio of a single element to the sum of the other elements present[22] (Table 5). The error of the method is approximately $10 \%$.

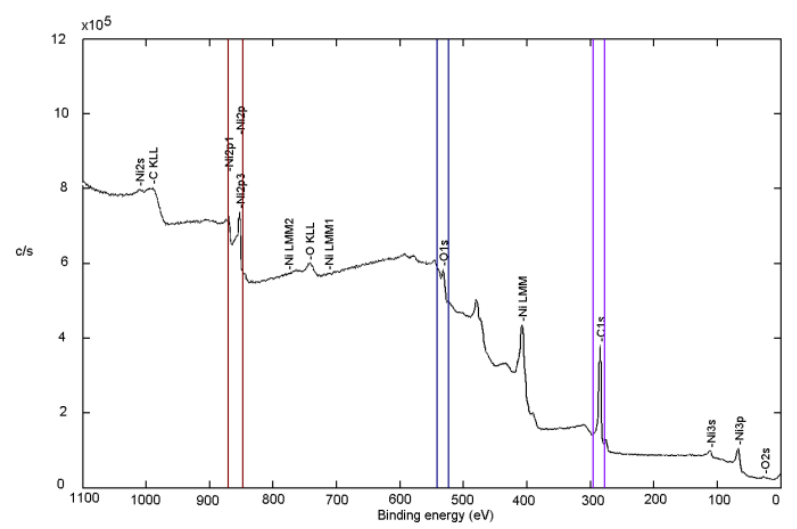

a)

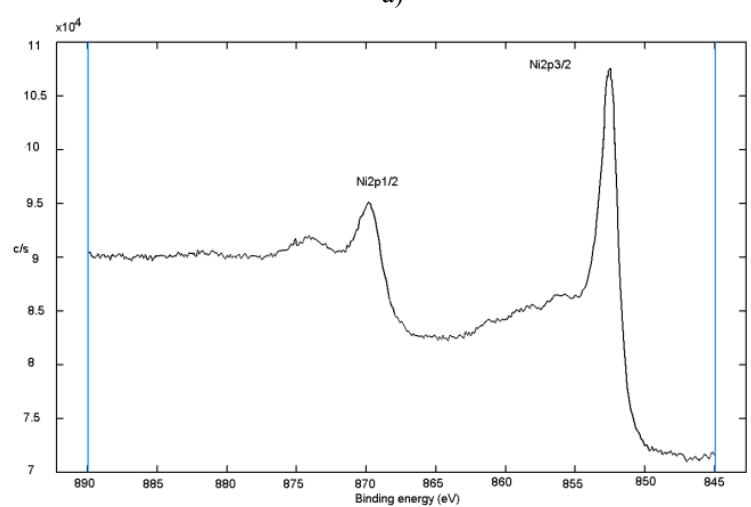

b)

Figure 3. XPS spectrum of Biomorphic NiO: a) survey b) Ni2p spectrum $(852.5 \mathrm{eV})$

Table 5. Atomic concentration obtained from XPS

\begin{tabular}{cccc}
\hline Element & Area (cts-eV/s) & Concentration (\%) & \% Mass \\
\hline $\mathrm{C} 1 s$ & 133629 & 80.45 & 54.86 \\
$\mathrm{O} 1 s$ & 34357 & 8.26 & 7.5 \\
$\mathrm{Ni} 2 p$ & 259380 & 11.29 & 37.63 \\
\hline
\end{tabular}

\subsection{Sample Dissolution}

The principal problem in the determination of metal species present in the biomorphic ceramic is their difficult dissolution of the samples due to the high resistance of these advanced ceramics to thermal and chemical attack. Although decomposition by alkali fusion can be used, this procedure is slow and implies the use of a platinum crucible[23], and the presence of an excess of solid fusion reagent. For this reason, in the present work dissolution has been achieved by acid attack under microwave-assisted pressure digestion.

The advantages of microwave dissolution include faster reaction rates that result from the high temperature and pressures attained inside the sealed containers. The use of closed vessels makes it possible to eliminate uncontrolled trace element losses of volatile molecular species that are present in a sample. Another advantage of microwave dissolution is a decrease in blank values as compared to open-beaker work, both because contamination from the laboratory environment is much lower and because closed vessels make it possible to use smaller quantities of reagents.

On the other hand, factorial design approach is a useful tool to establish and improve analytical procedures. Although it seems more complex than the univariate procedure from the operative point of view, it is advantageous since it makes use of fewer experiments and provides important information on interactions among the studied variables[24, 25]. A three-level full factorial $3^{3}$ with 27 runs was carried out in order to determine the main factors of the microwave-assisted biomorphous NiO-ceramic digestion. The significance of the effects was checked by analysis of the variance (ANOVA) and using p-value significance levels. This value represents the probability of the effect of a factor being due solely to random error. Thus, if the p-value is less than $5 \%$, the effect of the corresponding factor is significant.
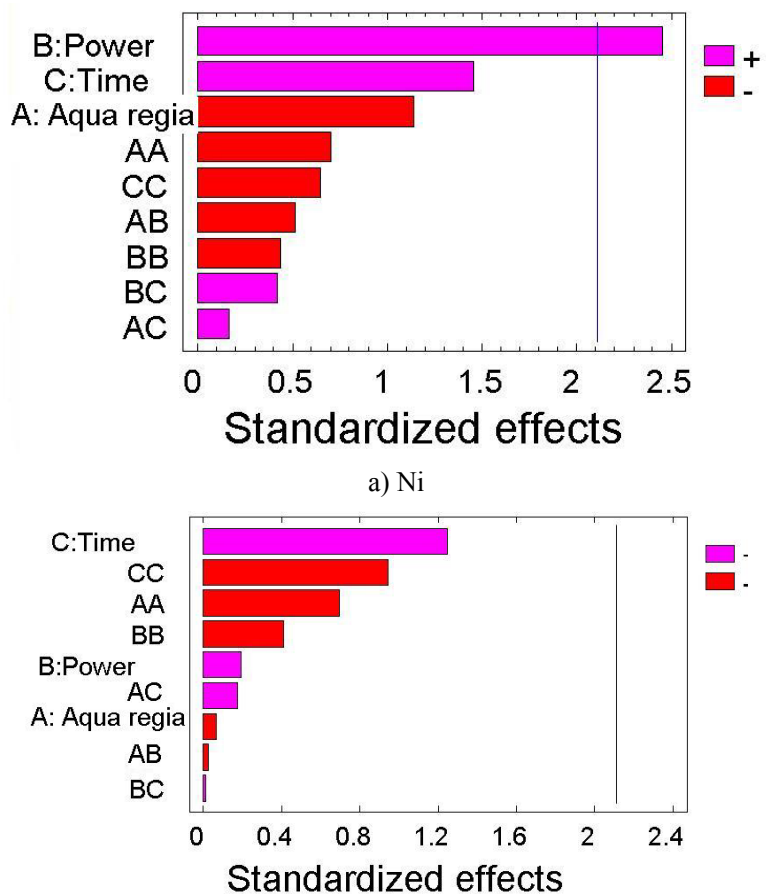

b) $\mathrm{Ca}$

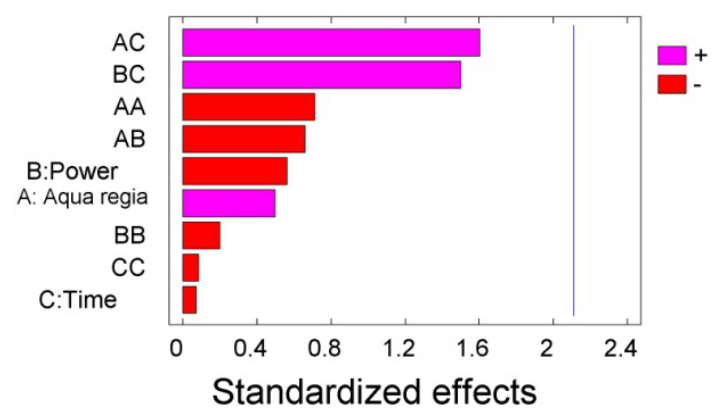

c) $\mathrm{Mg}$

Figure 4. Pareto charts for: a) $\mathrm{Ni}$; b) $\mathrm{Ca}$; c) $\mathrm{Mg}$

The results of the ANOVA carried out on the data given in Table 4 are shown in Table 6 . The two-order effect combined Pareto charts $(\mathrm{P}=95 \%)$ were obtained for the three factors considered (Figure 4). Also, the ANOVA results produced the graphs showing the influence of main effects represented 
in Figure 5 and interaction plot in Figure 6. After the analysis of the results, it was observed that the studied variables have no significant effects for $\mathrm{Ca}$ and $\mathrm{Mg}$ however significant effect was demonstrated for power in the case of Ni. On the other hand, the results obtained fit the equations display in Table 7 for each element determined.

Table 6. p-Value from ANOVA

\begin{tabular}{||c|c|c|c||}
\hline Source & P-Value $(\mathrm{Ni})$ & P-Value $(\mathrm{Ca})$ & P-Value $(\mathrm{Mg})$ \\
\hline A: AR & 0.2706 & 0.9550 & 0.6265 \\
\hline B: Power & 0.0257 & 0.8544 & 0.5848 \\
\hline C: Time & 0.1648 & 0.2294 & 0.9460 \\
\hline AA & 0.4960 & 0.4993 & 0.4901 \\
\hline AB & 0.6168 & 0.9823 & 0.5212 \\
\hline AC & 0.8751 & 0.8682 & 0.1283 \\
\hline BB & 0.6717 & 0.6914 & 0.8484 \\
\hline BC & 0.6808 & 0.9948 & 0.1526 \\
\hline CC & 0.5292 & 0.3608 & 0.9377 \\
\hline
\end{tabular}

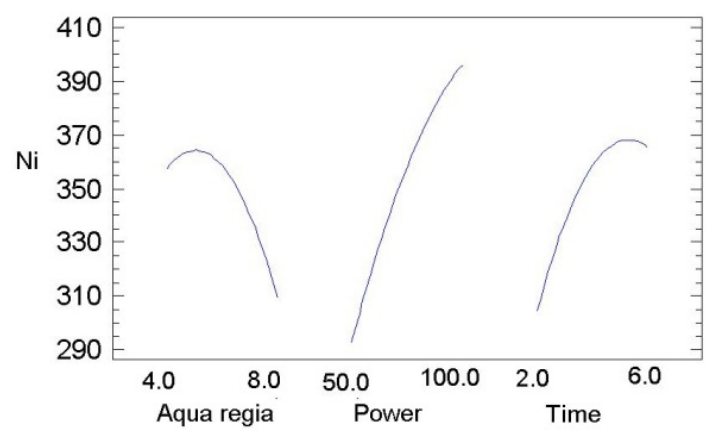

a)

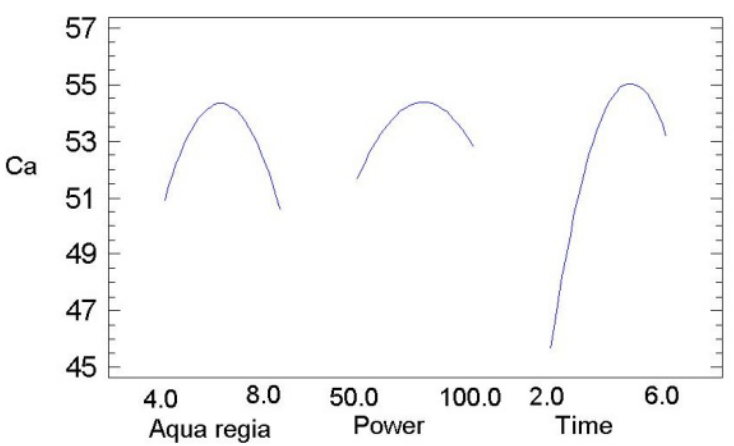

b)

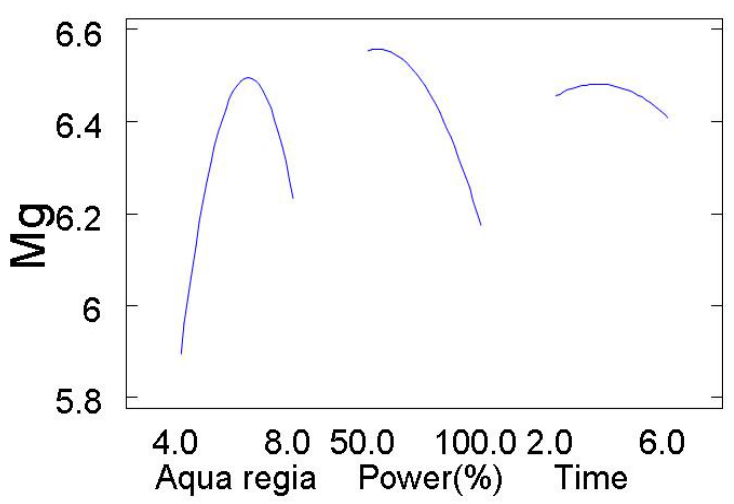

c)

Figure 5. Main effects for: a) $\mathrm{Ni}$; b) $\mathrm{Ca}$; c) $\mathrm{Mg}$
Table 7. Equations obtained for each element

\begin{tabular}{|c|}
\hline $\mathrm{Ni}(\mathrm{mg} / \mathrm{g})=-283.998+80.4835 \cdot \mathrm{X}+6.61028 \cdot \mathrm{Y}+40.1536 \cdot \mathrm{Z}-$ \\
$6.40292 \cdot \mathrm{X}^{2}-0.265383 \cdot \mathrm{X} \cdot \mathrm{Y}+1.03875 \cdot \mathrm{X} \cdot \mathrm{Z}-0.0254053 \cdot \mathrm{Y}^{2}+$ \\
$0.217867 \cdot \mathrm{Y} \cdot \mathrm{Z}-5.9125 \cdot \mathrm{Z}^{2}$ \\
\hline $\mathrm{Ca}(\mathrm{mg} / \mathrm{g})=-24.4711+11.7115 \cdot \mathrm{X}+0.614289 \cdot \mathrm{Y}+12.2699 \cdot \mathrm{Z}-$ \\
$1.03167 \cdot \mathrm{X}^{2}-0.0019 \cdot \mathrm{X} \cdot \mathrm{Y}+0.178021 \cdot \mathrm{X} \cdot \mathrm{Z}-0.00386267 \cdot \mathrm{Y}^{2}+$ \\
$0.000558333 \cdot \mathrm{Y} \cdot \mathrm{Z}-1.40354 \cdot \mathrm{Z}^{2}$ \\
\hline $\mathrm{Mg}(\mathrm{mg} / \mathrm{g})=6.91333+1.07292 \cdot \mathrm{X}+0.0027 \cdot \mathrm{Y}-1.85021 \cdot \mathrm{Z}-$ \\
$0.10375 \cdot \mathrm{X}^{2}-0.00545 \cdot \mathrm{X} \cdot \mathrm{Y}+0.16625 \cdot \mathrm{X} \cdot \mathrm{Z}-0.000182667 \cdot \mathrm{Y}^{2}+$ \\
$0.0124583 \cdot \mathrm{Y} \cdot \mathrm{Z}-0.0116667 \cdot \mathrm{Z}^{2}$ \\
\hline
\end{tabular}

$\mathrm{X}=$ Aqua Regia $(\mathrm{mL}) ; \mathrm{Y}=$ Power $(\mathrm{W}) ; \mathrm{Z}=$ Time $(\mathrm{min})$

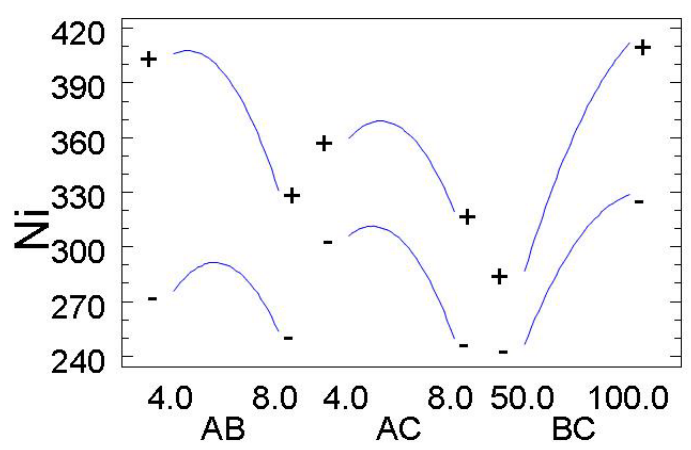

a)

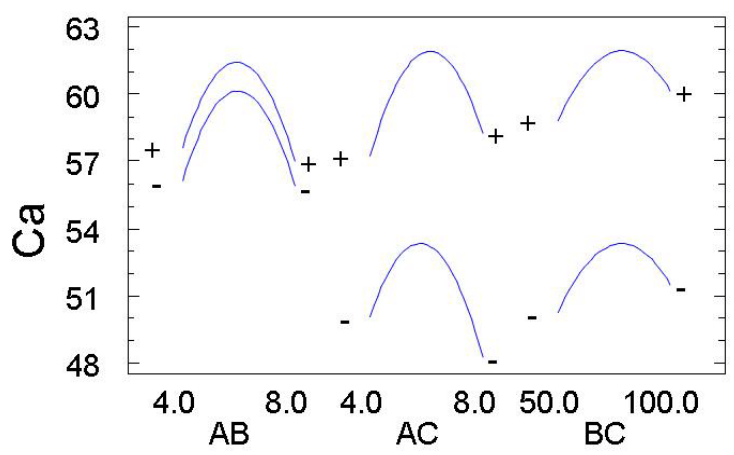

b)

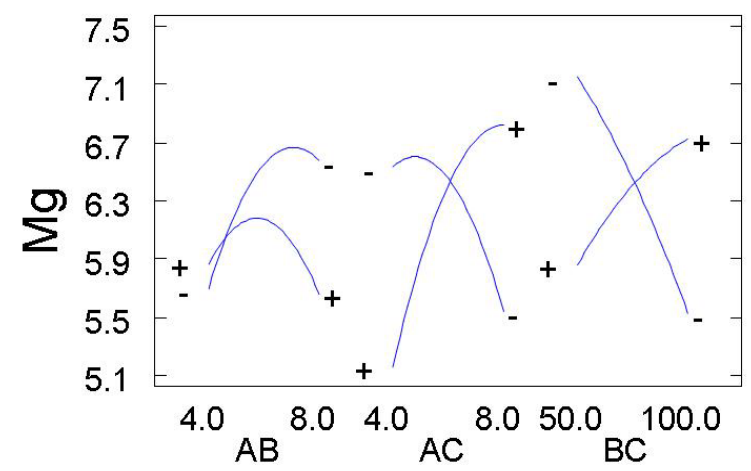

c)

Figure 6. Interaction plots for: a) $\mathrm{Ni}$; b) $\mathrm{Ca}$; c) $\mathrm{Mg}$

\section{Conclusions}

In this work, we have synthesized a ceramic material by infiltration with $\mathrm{Ni}\left(\mathrm{NO}_{3}\right)_{2} \cdot 6 \mathrm{H}_{2} \mathrm{O}$ from beech wood by using a slight modification of a previously described procedure[18]. The determination of metal ions in these ceramics can be achieved by the dissolution in acids under microwave irra- 
diation, followed by the analysis of FAAS, although the dissolution step is time-consuming and the use of high purity acids is absolutely necessary. Dissolution under microwave irradiation shortens appreciably the time of the acid attack. Different acid mixtures were tested for the samples digestion processes $\left(\mathrm{HCl}, \mathrm{HF}, \mathrm{HNO}_{3}\right.$ and $\left.\mathrm{H}_{2} \mathrm{SO}_{4}\right)$ and the mixture $\left(3 \mathrm{HCl}+1 \mathrm{HNO}_{3}\right.$, aqua regia) was selected in order to obtain maxima concentration of the ions. The application of factorial design allowed the optimization of parameters that influence the performance of microwave-assisted acid digestion procedures. Employing the Pareto's charts, it was possible to evaluate the influence of each variable and the combination of variables in the metallic ion concentrations.

\section{ACKNOWLEDGEMENTS}

The authors thank to the Ministerio de Ciencia e Innovación for supporting this study (Projects CTQ200907858) and also the Junta de Andalucia.

\section{REFERENCES}

[1] Fan T.X., Chow S.K., Zhang D., Progress Mater. Sci.,(2009) $54,542$.

[2] Greil P., Lifka T., Kaindl A., J. Eur. Ceram. Soc., (1998) 18, 1975.

[3] Gurfinkel G., Wood Engineering, 2nd ed. Kendall/Hunt, Dubuque, Iowa, 1981.

[4] Gibson E.J., Met. Mater., (1992) 6, 333.

[5] Lucas P.W., Darvell B.W., Lee P.K., Yuen T.D.B., Choong M.F., Phil. Trans., (1995) B348, 363.

[6] Ota T., Takahashi M., Hibi T., Ozawa M., Suzuki S., Hikichi Y., J. Am. Ceram. Soc., (1995) 78, 3409.

[7] Greil P., T. Lifka, A. Kaindl, J. Eur. Ceram. Soc., (1998) 18,
1961.

[8] Vogli E., Mukerji J., Hoffmann C., Kladny R., Sieber H., Greil P., J. Am. Ceram. Soc., (2001) 84, 1236.

[9] Qian J., Wang J., Jin Z., Mater. Sci. Eng. A, (2004) 371, 229.

[10] Esposito L., Sciti D., Piancastelli A., Bellosi A., J. Eur. Ceram. Soc., (2004) 24, 533.

[11] Sun B., Fan T., Zhang D., J. Porous Mater., (2002) 9, 275.

[12] Sun B., Fan T., Zhang D., Carbon, (2003) 42, 177.

[13] Yongsoon S., Liu J., Chang J.H., Nie Z., Exarhos J.G., Adv. Mater., (2001) 13, 728.

[14] Cao J., Rambo C.R., Sieber H., J. Porous Mater., (2004) 11, 163.

[15] Ota T., Imaeda M., Takase H., Kobayashi M., Kinoshita N., Hirashita T., J. Am. Ceram. Soc., (2000) 83, 1521.

[16] Fan T., Li X., Liu Z., Gu J., Zhang D., Guo Q., J. Am. Ceram. Soc., (2006) 89, 3511.

[17] Li X., Fan T., Liu Z., Ding J., Guo Q., Zhang D., J. Eur. Ceram. Soc., (2006) 26, 3657.

[18] Liu Z., Fan T., Zhang D., J. Am. Ceram. Soc., (2006) 89, 662.

[19] Rambo C.R., Cao J., Sieber H., Mater. Chem. Phys., (2004) 87,345 .

[20] Singh M., Yee B.M., J. Eur. Ceram. Soc., (2004) 24, 209.

[21] Statgraphics Plus version 5.1, Reference Manual, Manugistics, Rockville, MD, 1992.

[22] Physical Electronics, Multitechnique ESCA Reference manual for the PCACCES Software Version 6.0, Physical Electronics, Minneapolis, USA, 1995.

[23] Mann S., Geilenberg D., Broekaert J.A.C., Jansen M., J. Anal. At. Spectrom., (1997)12, 975.

[24] Nechar M., Molina M.F., Bosque-Sendra J.M., Anal. Chim. Acta (1999) 382, 117.

[25] Costa L.M., Ferreira S.L.C., Nogueira A.R.A., Nóbrega J.A., J. Braz. Chem. Soc., (2005) 16, 1269. 